\title{
OCORRÊNCIA DO CASSAVA COMMON MOSAIC VIRUS (CsCMV) \\ E CASSAVA VEIN MOSAIC VIRUS (CsVMV) EM CULTIVARES DE MANDIOCA EM SANTA CATARINA, BRASIL
}

\author{
A. Colariccio ${ }^{1 *}$, E.B. Rivas ${ }^{1}$, M.F. Bonfim Junior ${ }^{2}$, L.A.M. Peruch ${ }^{3}$ \\ ${ }^{1}$ Instituto Biológico, Centro de Pesquisa de Sanidade Vegetal, Av. Cons. Rodrigues Alves, 1252, CEP 04014-900, \\ São Paulo, SP, Brasil; Epagri, Estação Experimental de Urussanga, Rod. SC 108, Km353, n 1563 ,

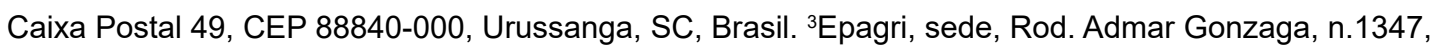 \\ Florianópolis, SC, Brasil. *E-mail: colariccio@biologico.sp.gov.br
}

\section{RESUMO}

O cultivo da mandioca é realizado na maioria dos municípios e estados brasileiros, sendo uma pequena parte destinada ao consumo in natura e a maior parte para a produção de farinha e extração de amido. Embora seja uma planta rústica, diversos fatores bióticos e abióticos podem reduzir a produtividade da cultura. As doenças viróticas causam impacto na cultura, principalmente devido a eficiente disseminação do patógeno por meio da propagação vegetativa das manivas infectadas e degenerescência das raízes. No Brasil já foram relatados o Cassava common mosaic virus (CsCMV), Cassava vein mosaic virus (CsVMV), e Cassava frogskin disease, destacando-se os dois primeiros como os mais disseminados no país. Neste trabalho foi avaliada a ocorrência de vírus em 17 cultivares de mandioca, cultivadas comercialmente em Urussanga, Jaguaruna e Sangão, região Sul de Santa Catarina. A detecção de vírus em amostras foliares, apresentando mosaico severo, bolhosidades e distorção foliar, foi realizada por RT-PCR para CsCMV e por PCR para CsVMV. Ensaios de transmissão mecânica para espécies indicadoras foram realizados em condições de laboratório. Os vírus CsCMV e CsVMV foram detectados co-infectando as cvs 'Mandin', 'Sangão', 'Vermelhinha', 'Ajubá', 'Guapo', 'Seleto' e 'Mantiqueira' cultivadas em Urussanga e Sangão. A infecção pelo CsCMV foi detectada nas cultivares 'Espetinho', 'Sambaqui', 'Olho Junto' em Sangão; nas 'Oeste', 'Uirapuru', 'Luna', 'Mandin’em Urussanga e na 'IAC90' em Jaguaruna e não houve detecção de vírus na 'Sambaqui' em Jaguaruna. Os resultados mostram a prevalência do CsCMV nas cultivares de mandioca avaliadas em Santa Catarina.

PALAVRAS-CHAVE: Manihot esculenta, identificação de vírus, infecção mista. 


\title{
OCCURRENCE OF CASSAVA COMMON MOSAIC VIRUS (CsCMV) AND CASSAVA VEIN MOSAIC VIRUS (CsVMV) ON CASSAVA CULTIVARS IN SANTA CATARINA, BRAZIL
}

\begin{abstract}
Cassava is grown in most Brazilian municipalities and states, with a small portion intended for fresh consumption and most for flour production and starch extraction. Although it is a rustic plant, several biotic and abiotic factors can reduce crop yield, with virus diseases having the greatest impact, mainly due to the efficient spread of the pathogen through vegetative propagation of infected manivas and root degeneration. Cassava common mosaic virus (CsCMV), Cassava vein mosaic virus (CsVMV), and Cassava frogskin disease have been reported in Brazil, but the first two are considered the most widespread in the country. In this work, virus occurrence was evaluated in 17 commercially cultivated cassava cultivars from Urussanga, Jaguaruna, and Sangão, municipalities of South region of Santa Catarina. Virus detection from leaf samples showing severe mosaic, blistering, and leaf distortion was performed by RT-PCR for CsCMV and PCR for CsVMV. Mechanical transmission assays in indicator species were evaluated under laboratory conditions. The CsCMV and CsVMV viruses were detected co-infecting the 'Mandin', 'Sangão','Vermelhinha', 'Ajubá', 'Guapo', 'Seleto' and 'Mantiqueira' cultivars grown in Urussanga and Sangão. Single infection by CsCMV was detected infecting the 'Espetinho', 'Sambaqui', 'Olho Junto' in Sangão; 'Oeste', 'Uirapuru', 'Luna', 'Mandin' Urussanga and 'IAC90' cultivars grown in Sangão, Urussanga and Jaguaruna. In 'Sambaqui' cultivar collected in Jaguaruna there was no virus detection. The results show the prevalence of CsCMV in cassava crops from Santa Catarina.
\end{abstract}

KEYWORDS: Manihot esculenta, virus identification, mixed infection 
A mandioca (Manihot esculenta Crantz), pertencente à família Euphorbiaceae, é uma espécie que foi domesticada, nas terras baixas e quentes da América, pelas populações pré-colombianas (VASCONCELOS, 2014). A planta é nativa do Brasil e acredita-se que durante os séculos XVI e XVII tenha sido amplamente disseminada pelos portugueses nas regiões tropicais e subtropicais da África, Ásia e Caribe (CARTER et al., 1993; VASCONCELOS, 2014).

A mandioca é um importante produto da agricultura brasileira, tanto por ser a base da alimentação para parte da população quanto por ser matéria-prima para os diferentes tipos de farinha produzidos no país (FELIPE, 2018). No Brasil há ainda muitos desafios na cadeia produtiva da mandioca e os dados da FAO mostram que houve um recuo na produção nacional de mandioca, que passou de 25,3 milhões de toneladas em 2011 para 20,1 milhões de toneladas em 2017 (FAO 2018). Um desses desafios é aumentar a produtividade da cultura, principalmente pelo desenvolvimento de novas cultivares. Diversos fatores bióticos e abióticos podem reduzir a produtividade da cultura. As doenças de origem viral merecem especial destaque em função de seu impacto na produtividade e por serem frequentemente disseminadas pela propagação vegetativa via manivas e ferramentas infectadas.

A propagação vegetativa na agricultura favorece a disseminação de doenças sistêmicas através das gerações su- cessivas, pois possibilita o acúmulo dos patógenos durante os sucessivos ciclos da cultura, como ocorre principalmente, com doenças causadas por vírus, que induzem a degenerescência do material empregado na propagação vegetativa (COSTA; KITAJIMA, 1972; ABREU et al., 2013).

No Brasil, o mosaico comum da mandioca causado pelo Cassava common mosaic virus (CsCMV) é o vírus mais comum da cultura, cujo agente causal pertence ao gênero Potexvirus e não tem vetor conhecido. A primeira detecção do CsCMV no Brasil foi relatada por SILBERSCHMIDT em 1938, sendo o mais disseminado em todas as regiões produtoras do país (ABREU et al., 2013; ABREU et al., 2015; PERUCH et al., 2015) e nos países sul-americanos (COSTA; KITAJIMA, 1972; CALVERT; THRESH, 2002). Além do CsCMV outras espécies também já foram relatadas no país, o Cassava vein mosaic virus (CsVMV), o Cassava frogskin associated virus (CFSV) e o Cassava symptomless virus (CsALV) (ALABI et al., 2011) e da associação dos sintomas do CFSV com a infecção mista de Cassava torradolike virus, Cassava polero-like virus e Cassava new alphaflexivirus associated (OLIVEIRA et al., 2019). Em Santa Catarina, o CsCMV foi identificada no Sul do Estado em 2008 (COLARICCIO et al., 2009) e está disseminada nos cultivos de todo o território catarinense (PERUCH et al., 2013). Nos principais países produtores do mundo já foi relatada a ocorrência de pelo menos 15 
espécies virais na cultura da mandioca (LEGG, et al., 2014). Apesar do registro da ocorrência de uma espécie de Begomovirus no Brasil (COSTA et al., 2008) é importante salientar que o African cassava mosaic virus, uma espécie de Geminivirus, é uma praga quarentenária ausente do país (Instrução Normativa $\mathrm{n}^{\circ} 39$ de 01/10/2018), mas cujo vetor, Bemisia tuberculata ocorre no país (BARILLI et al., 2015).

Este trabalho teve por objetivo avaliar a ocorrência de CsCMV e CsVMV em 17 cultivares de mandioca, comercialmente cultivadas para consumo in natura e para a fabricação de farinhas, nos municípios de Urussanga, Jaguaruna e Sangão, Região Sul de Santa Catarina. Foram coletadas folhas com sintomas de mosaico severo, bolhosidade e distorção foliar (Figura 1) e folhas assintomáticas. Essas amostras foram submetidas a testes biológicos e moleculares (RT-PCR e PCR). Para a preparação do inóculo, fragmentos de folhas de mandioca foram triturados em presença de tampão fosfato de sódio e potássio $0,05 \mathrm{M}, \mathrm{pH}$ 7,4 , com $0,5 \%$ de sulfito de sódio, sendo mecanicamente inoculados em folhas jovens de Chenopodium amaranticolor e Gomphrena globosa (Amaranthaceae). Após a inoculação, as plantas foram mantidas em casa de vegetação para avaliação quanto a presença de sintomas.

Considerando que entre os vírus que infectam a mandioca o genoma pode ser de RNA ou DNA, foram realizadas extrações tanto de DNA, quanto de RNAs totais das amostras foliares.
As extrações de RNA foram realizadas de acordo com o procedimento descrito por SALZMAN et al. (1999). Esses RNAs foram utilizados em RT-PCRs (Reverse Transcription - Polymerase Chain Reaction) com primers dirigidos para a ORF 1 de Potexvirus (GIBBS et al., 1998), para a detecção de CsCMV. Os DNAs totais, extraídos conforme descrito por DELLAPORTA et al. (1983), foram utilizados em PCRs com primers dirigidos para as regiões transcriptase reversa e ribonuclease $\mathrm{H}$ de Badnavirus (YANG et al., 2003). As reações de transcrição reversa (RT) foram realizadas com GoScript $^{\mathrm{TM}}$ Reverse Transcription System (Promega), conforme descrito pelo fabricante. As PCRs foram realizadas com GoTaq $^{\circledR}$ G2 Hot Start Green Master Mix. Os produtos da PCR foram analisados eletroforeticamente em gel de agarose 1,5\%, em tampão TAE 1x, e visualizados em um transiluminador UV.

Houve manifestação de sintomas nas plantas de $C$. amaranticolor e $G$. globosa que reagiram com lesão local, quando inoculadas com as amostras das cultivares 'IAC 90', 'Sambaqui', 'Espetinho'e 'Olho Junto'. Como o CsCMV induz lesões locais em $C$. amaranticolor e não induz lesão local em G. globosa, possivelmente, nessas cultivares há infecção por outro vírus, exceto para 'Olho Junto' que não induziu sintomas em G.globosa. Enquanto as amostras das cultivares de mandioca 'Ajubá', 'Guapo', 'Seleto', 'Mandim' e 'Uirapuru', não induziram sintomas nas plantas indicadoras empregadas neste trabalho. 
Tabela 1: Avaliação por ensaio biológico e molecular da ocorrência do Cassava common mosaic virus (CsCMV) e Cassava vein mosaic virus (CsVMV) em cultivares de mandioca coletadas em região produtora de Santa Catarina

\begin{tabular}{|l|c|r|c|}
\hline \multicolumn{1}{|c|}{ Cultivar/ Município } & Ensaio biológico & Ensaio molecular & Número da amostra \\
\hline 'IAC90'/ Jaguaruna & & CsCMV (+) & J1 \\
'Espetinho'/ Sangão & C. amaranticolor (-) & CsCMV (+) & S4 \\
'Sambaqui'/ Sangão & G. globosa (+) & CsCMV (+) & S8 \\
'Olho Junto'/ Sangão & & CsCMV (+) & S7 \\
\hline 'Oeste'/ Urussanga & & CsCMV (+) & U14 \\
'Uirapuru'/ Urussanga & C. amaranticolor (-) & CsCMV (+) & U21 \\
'Luna'/ Urussanga & G. globosa (+) & CsCMV (+) & U9 \\
'Mandim'/ Urussanga & CsCMV(+) & U10 \\
'Mandim'/ Sangão & & CsCMV/CsVMV(+) & S6 \\
\hline 'IAC90'/ Jaguaruna & C. amaranticolor(+) & CsCMV (+) & J2 globosa (+) \\
\hline & C. amaranticolor(+) & CsCMV (-) & J3 \\
'Sambaqui'/ Jaguaruna & G. globosa (+) & CsVMV (-) & U11 \\
\hline 'Sangão'/Urussanga & & & U12 \\
'Vermelhinha'/Urussanga & C. amaranticolor(+) & CsCMV/CsVMV (+) & U16 \\
'Ajubá'/Urussanga & G. globosa (+) & & U18 \\
'Guapo'/Urussanga & & & U19 \\
'Seleto'/ Urussanga & & & \\
\hline
\end{tabular}

Pelos resultados obtidos nos municípios de Urussanga, Jaguaruna e Sangão, no litoral Sul de Santa Catarina, a ocorrência da co-infecção pelo CsCMV e CsVMV foi detectada na cv. 'Mandim' coletada em Sangão e nas cvs. 'Sangão', 'Vermelhinha', 'Ajubá', 'Guapo', 'Seleto' e |Mantiqueira coletadas em Urussanga. A infecção simples pelo CsCMV foi detectada na cv. 'IAC90' coletada em Jaguaruna' e nas cvs 'Espetinho', 'Sambaqui', 'Olho Junto' coletadas em Sangão e nas cvs 'Oeste', 'Uirapuru', 'Luna' e 'Mandim' coletadas em Urussanga. Na cv. Sambaqui coletada em Jaguaruna não foi de- tectada a presença destes vírus (Tabela 1) e não foi detectada a ocorrência do Cassava frogskin disease, doença conhecida como pele de sapo, nas propriedades visitadas na região avaliada de SC. No Brasil, foi relatada a ocorrência de três vírus, em associação com a 'frogskin disease' (OLIVEIRA et al., 2019). Na avaliação realizada em Jaguaruna, SC verificou-se que o CsCMV tem uma prevalência, pois ocorreu com frequência maior do que o CsVMV, nas amostras e municípios avaliados. Resultado semelhante ao obtido por ABREU et al. (2015) nos principais estados produtores do Brasil. 
A primeira ocorrência do CsCMV no estado catarinense em Manihot esculenta foi relatada em material foliar proveniente de Urussanga, SC por COLARICCIO et al., (2009). Após a detecção destes vírus, em um levantamento realizado por PERUCH et al., (2015) foi detectada uma alta incidência do CsCMV em lavouras comerciais com $23 \%$ das plantas infectadas por este vírus nas regiões produtoras de Santa $\mathrm{Ca}$ tarina. Fato semelhante foi verificado nas regiões produtoras da Bahia, por ABREU et al., (2013), e nos estados do Nordeste onde o CsCMV também prevaleceu (ABREU et al., 2015). O CsCMV é o vírus mais disseminado nas principais regiões produtoras do país e têm potencial de causar perdas, pois impede o total desenvolvimento das plantas e interfere com a quantidade das raízes e a qualidade do amido produzido, em associação com a variedade cultivada, como foi verificado por VENTURINI et al., (2016). Apesar do impacto que os vírus podem causar nesta cultura, não existem dados precisos sobre a severidade dos sintomas e das perdas causadas pelo CsCMV e CsVMV nas cultivares avaliadas nessa região (COLARICCIO et al., 2009). Portanto, levantamentos fitopatológicos são trabalhos importantes por monitorar flutuações nas intensidades das doenças e verificar a eficiência e aceitação de práticas recomendadas de controle (KING, 1980). Uma das medidas para a manutenção da sanidade das plantas de mandioca no campo é a obtenção de plantas livres de vírus, pela técnica da cultura de tecidos, associada à termoterapia (PALAZZO et al., 2006). A técnica possibilitou a obtenção de matrizes livres de vírus para as matrizes do Banco de Germoplasma do IAC, as quais puderam ser multiplicadas e plantadas pelos produtores em São Paulo (SOARES et al., 2009). Considerando a relevância da disseminação do CsCMV e do CsVMV nos cultivos comerciais de mandioca dos três municípios avaliados considera-se importante adotar várias práticas de controle da doença, desde os cuidados na seleção e manejo das ramas, assepsia das ferramentas empregadas no corte das manivas até o uso de cultivares geneticamente melhoradas e o cultivo de matrizes livres de vírus. Estas práticas aliadas ao uso de cultivares resistentes aos vírus, podem contribuir para reduzir a degenerescência da raiz, aumentando a qualidade da mesma e originando produtos como fécula e farinha com melhor qualidade.

\section{Considerações finais}

Prevalência da infecção simples pelo CsCMV e da sua co-infecção com o CsVMV, em Santa Catarina, Brasil;

Não houve detecção do Cassava frogskin disease em Santa Catarina, Brasil. 


\section{REFERÊNCIAS}

ABREU, E.F.M.; CERQUEIRA, L. R. S.; FERNANDES, A. M. Prevalência dos vírus CsVMV (Cassava vein mosaic virus) e CsCMV (Cassava common mosaic virus) em regiões produtoras de mandioca no Brasil. In: Congresso Brasileiro de Mandioca, Congresso Latino-Americano e Caribenho de Mandioca, 16, 2015. Anais...Foz do Iguaçu, 2015. CD-Rom.

ABREU, E. F. M.; FRÓES, T. L.; FERNANDES, A.M.; AMARAL, C. M.; LARANJEIRA, F. F.; MEISSNER FILHO, P. E. Estudo de prevalência do Cassava commom mosaic vírus (CsCMV) e do Cassava vein mosaic virus (CsVMV) na região Produtora do estado da Bahia. In: Congresso Brasileiro de Mandioca, 15, Anais. Botucatu- SP: SBM, 2013.

ALABI, O.J.; KUMAR, P.L.; NAIDU, R.A. Cassava mosaic disease: A curse to food security in Sub-Saharan Africa. APSnet Features. doi: 10.1094/APSnetFeature-2011-0701, 2011.

BARILLI, D. R.; RINGENBERG, R.; PIETROWSKI, V.; WEBER, P. Biologia da mosca branca Bemisia tuberculata (BONDAR, 1923) (HEMIPTERA: ALEYRODIDAE) em mandioca (Manihot esculenta). In Jornada Científica, 9 - Embrapa Mandioca e Fruticultura, 2015.

CALVERT, L.A.; THRESH, J.M. The Viruses and virus diseases of cassava.In: J.HILLOCKS, J.M. THRESH AND A.C. BELLOTTI (Eds). Cassava: Biology, production and utilization. CAB International, chapter 12, p.237-260, 2002.

CARTER, S.E.; FRESCO, L.O.; JONES, P.G.; FAIRBAIRN, J.N. Introduction and diffusion of cassava in Africa. IITA Research Guide, n 49, 33p., 1993.

CHOI, S.K.; CHOI, J.K.; PARK, W.M.; RYU, K.H. RT-PCR detection and identification of three species of cucumoviruses with a genus-specific single pair of primers. Journal of Virological Methods, v. 83, p.67-73, 1999.

COLARICCIO, A.; PERUCH, L.A.M.; PEREIRA, L.S.; POLA, A.C.; NEUBERT, E. Primeiro relato do mosaico comum da mandioca em Santa Catarina. In: Congresso Brasileiro de Mandioca, 13, 2009. Anais Botucatu-SP, 2009.

COSTA, G.M.; FONSECA, M. E. N.; INOUE-NAGATA, A. K.; LIMA NETO, A. F.; BOITEUX, L. S. Infecção de Begomovirus em mandioca (Manihot esculenta subsp. esculenta) no Brasil. Horticultura brasileira, v. 26, n. 2 (Suplemento - CD Rom), 2008.

COSTA, A.S. \& KITAJIMA, E.W. Description of Plant Viruses. CMI/AAB nº 90, 1972

COSTA, A.S. Observações sobre o mosaico comum e mosaico das nervuras da mandioca (Manihot utilissima Pohl.). Jornal Agronomia, Piracicaba, p. 239-248, 1940

DELLAPORTA, S.L.; WOOD, J.; HICKS, J.B. A plant DNA minipreparation: version II. Plant Molecular Biology Reporter, v.1, p.19-21, 1983.

FAOSTAT. Crops. Disponível em: <http://www.fao.org/faostat/en/\#data/oc>. Acesso em: 18 set. 2019.

FELIPE, F.I. Produção de mandioca - raiz, farinha e fécula. Caderno setorial ETENE, v.3, n.44, p.1-10, 2018. 
GIBBS, A.; ARMSTRONG, J.; MACKENZIE, A. M.; WEILLER, G. F. The GPRIME package: computer programs for identifying the best regions of aligned genes to target in nucleic acid hybridisationbased diagnosis tests, and their use with plant viruses. Journal of Virological Methods, v.74, p.67-76, 1998.

LEGG, J.P.; LAVA KUMAR, P.; MAKESHKUMAR, T.; FERGUSON, M.; KANJU, E.; NTAWURUHUNGA, P.; CUELLAR, W. Cassava virus diseases: biology, epidemiology and management. Advances in Virus Research 91: 85-142, 2014.

OLIVEIRA, S. A. S.; FERREIRA, C. F.; DIAMANTINO, M. S. A. S.; SANTOS, T. A.; PEREIRA, J.S.; OLIVEIRA, E.J. First report of Cassava torrado-like virus, Cassava polero-like virus and Cassava new alphaflexivirus associated with Cassava frogskin disease in Brazil. Journal of Plant Pathology, 2019. doi.org/10.1007/s42161-019-00384-6

PALAZZO, S.R.L., VALLE, T.L., FELTRAN, J.C., COLARICCIO, A. Eliminação do Cassava common mosaic virus - CsCMV por cultura de meristema associada a termoterapia. O Biológico, São Paulo, v.68, Suplemento, p.626-629, 2006.

PERUCH, L.A.M.; COLARICCIO, A.; MORETO, A.L.; NEUBERT, E.O.; PEREIRA, E.F. Sintomas e controle das principais doenças da mandioca em Santa Catarina. Revista agropecuária Catarinense, v.26, n.2, p.52-54, 2013.

PERUCH, L.A.M.; MORETO, A.L.; NEUBERT, E.O.; PEREIRA, E.F.; NUNES, E.C. Levantamento da intensidade das doenças da mandioca em cultivos no estado de Santa Catarina. In: Congresso Brasileiro de Mandioca, 16, 2015. Anais...Foz do Iguaçu, 2015. CD-Rom

SALZMAN, R.A.; FUJITA, T.; ZHU-SALZMAN, K.; HASEGAWA, P.M.; BRESSAN, R.A. An improved RNA isolation method for plant tissues containing high levels of phenolic compounds or carbohydrates. Plant Molecular Biology Reporter, v.17, p.11-17, 1999.

SILBERSCHMIDT, K.M. O mosaico da mandioca. O Biológico, V.IV, n.6, p. 177-181, 1938.

SOARES, M. B. B.; VALLE, T. L.; COLARICCIO, A.; FELTRAN, J.C.; VAZLOBO, R.S.; MARTINS, A.L.M. DISSEMINAÇÃO DO VÍRUS DO MOSAICO-COMUM EM ÁREA DE MANDIOCA (MANIHOT ESCULENTA CRANTZ.) In: Congresso Brasileiro de Mandioca, 13, 2009. Anais Botucatu-SP, 2009.

VASCONCELOS, B.R. O setor de amido de mandioca brasileiro e a importância das geotecnologias para estabilização na oferta de mandioca. In: Congresso de Geógrafos, 7, 2014. Suplemento, Vitória, ES, 2014.

VENTURINI, M. T.; ARAÚJO, T.S.; ABREU, E. F. M.; ANDRADE, E. C.; SANTOS, V. S.; SILVA, M. R.; OLVEIRA, E. J. Crop losses in Brazilian cassava varieties induced by the Cassava common mosaic vírus. Sci. Agric. v.73, n.6, p.520-524, 2016.

YANG, I.C.; HAFNER, G.J.; DALE, J.L.; HARDING, R.M. Genomic characterization of taro bacilliform virus. Archives of Virology, v.148, p.937-949, 2003. 


\section{FIGURAS}
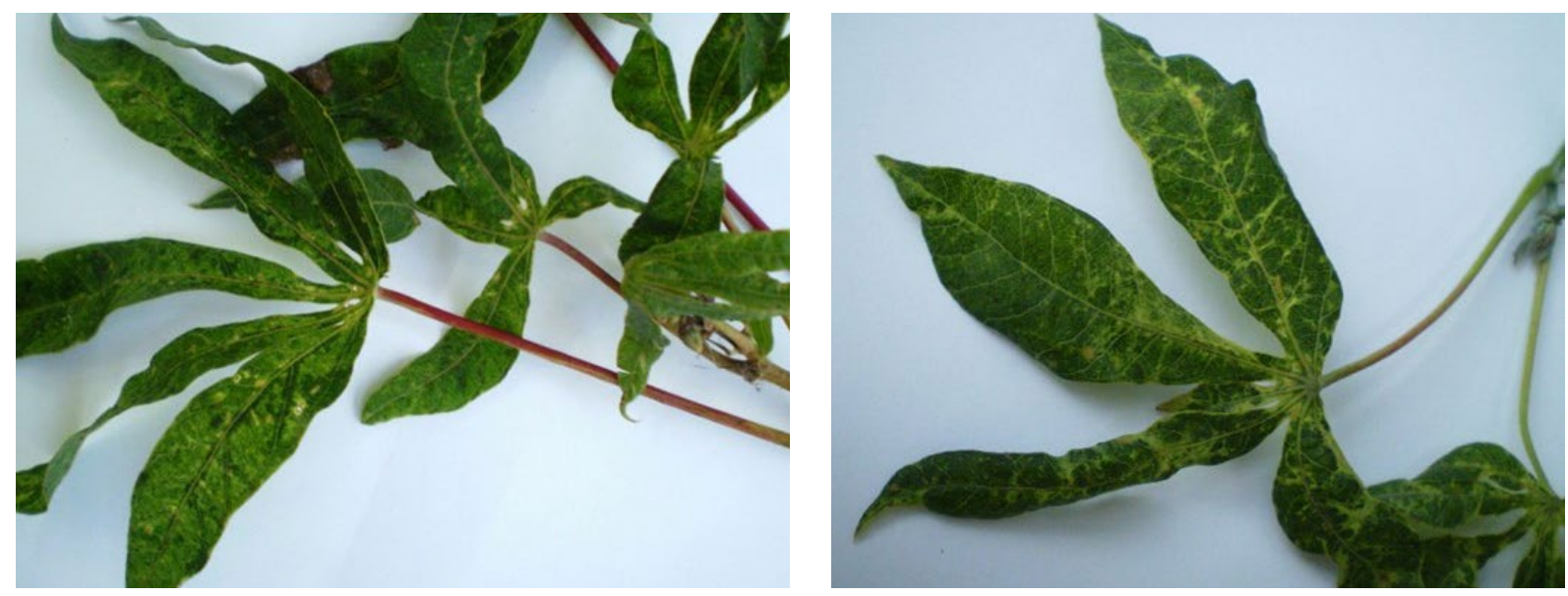

Figura 1 - Folhas de mandioca infectadas pelo Cassava common mosaic virus (CsCMV) A- Manihot esculenta cv. 'Mandin' coletada em Urussanga com sintomas de mosaico difuso; B- Manihot esculenta cv. 'Luna' coletada em Urussanga com mosaico bolhoso.
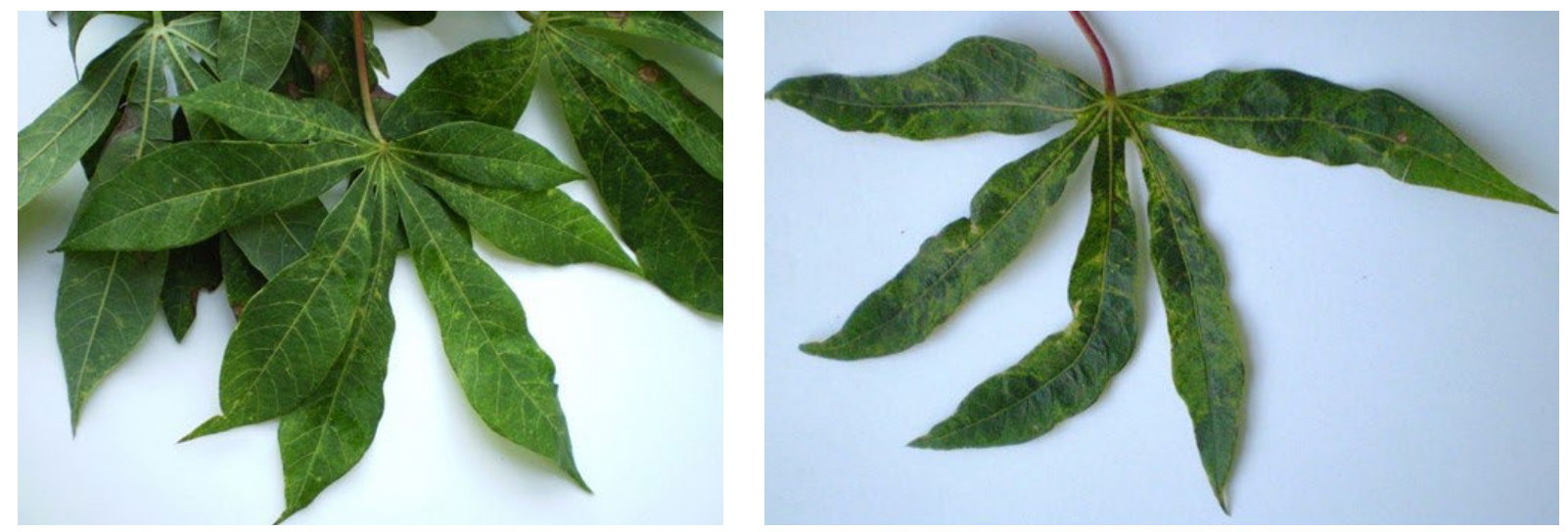

Figura 2 - Folhas de mandioca co-infectadas pelo CsCMV e pelo Cassava vein mosaic virus (CsVMV): A- Manihot esculenta cv. 'Mantiqueira' coletada em Urussanga com sintomas de mosaico bolhoso e redução do limbo foliar. B- Manihot esculenta cv. 'Mandin' coletada em Sangão com sintomas de mosaico bolhoso, redução e distorção do limbo foliar. 